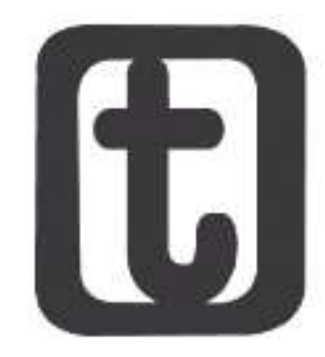

\title{
FORMAÇÃO PROFISSIONAL E CONSERVADORISMO: UMA ANÁLISE A PARTIR DOS/AS ESTUDANTES DO CURSO DE SERVIÇO SOCIAL DO INSTITUTO FEDERAL DE EDUCAÇÃO CIÊNCIA E TECNOLOGIA DO CEARÁ
}

\author{
Professional training and conservatives: an analysis from the students of the social service \\ course of the federal institute of education science and technology of Ceará
}

\author{
Ana Samilly Alexandre Moreira* \\ Mônica Ivo de Oliveira**
}

\begin{abstract}
RESUMO
O Serviço Social é uma profissão que historicamente se constituiu sob bases conservadoras. Estas, nunca deixaram de permear a formação e o exercício profissional apesar dos avanços feitos pela categoria, não sendo também, o conservadorismo, uma exclusividade desta profissão, mas própria da dinâmica de reprodução do capital. O seu avanço e reatualização na sociedade exige uma urgente e imprescindível reflexão acerca dos seus rebatimentos para o Serviço Social. Assim, o presente estudo tem como objetivo geral compreender as incisões do conservadorismo na formação profissional, tendo como lócus de pesquisa o curso de Serviço Social do Instituto Federal de Educação Ciência e Tecnologia do Ceará (IFCE) Campus Iguatu. A pesquisa, de caráter qualitativo, utilizou como procedimentos metodológicos a pesquisa bibliográfica, documental e de campo, esta última realizada com estudantes do sétimo e oitavo semestres e apresentou os seguintes resultados: os/as estudantes possuem conhecimento razoável acerca do conservadorismo e de suas formas de expressão na sociedade e na profissão, o conservadorismo tem se expressado principalmente a partir de posturas moralistas e preconceituosas por parte de estudantes e funcionários/a da instituição, além do crescimento de vertentes tidas como conservadoras pelas análises da vanguarda profissional. Em relação às pautas societárias, os/as estudantes entrevistados/as se posicionam, majoritariamente, em consonância com o que tem apontado o projeto de profissão do Serviço Social.
\end{abstract}

\section{PALAVRAS-CHAVE}

Serviço Social; Formação Profissional; Conservadorismo.

\footnotetext{
* Assistente Social. Especialista em Serviço Social, Políticas Públicas e Seguridade Social. Mestranda em Serviço Social, Trabalho e Questão Social pela Universidade Estadual do Ceará (UECE). Possui afinidade às seguintes temáticas: conservadorismo; direção ético-política e formação profissional em Serviço Social. Professora do curso de Serviço Social da Universidade Estadual do Ceará (UECE, Fortaleza, Brasil). Avenida Silas Mugumba, 1700, Itapety, Fortaleza (CE), CEP.: 60741-000. ORC ID: https://orcid.org/0000-0002-2491075X. E-mail: <assamilly@gmail.com>.

** Assistente Social. Mestrado profissional em andamento em Mestrado em Políticas Públicas com Ênfase em Saúde. Professora da Faculdade de Excelência (FAEX, Maranguape, Brasil). Av. Dr. Argel Gurgel, 960, Maranguape (CE), CEP.: 61942-280. ORC ID: https://orcid.org/0000-0002-2491-075X. E-mail: $<$ monica.ivo@hotmail.com>.
}

DOI 10.22422/temporalis.2019v19n37p151-171

(cc) Br ${ }_{\odot}$ A(s) Autora(s)/O(s) Autor(es). 2019 Acesso Aberto Esta obra está licenciada sob os termos da Licença Creative Commons Atribuição 4.0 Internacional (https://creativecommons.org/licenses/by/4.o/deed.pt_BR), que permite copiar e redistribuir o material em qualquer suporte ou formato, bem como adaptar, transformar e criar a partir deste material para qualquer fim, mesmo que comercial. O licenciante não pode revogar estes direitos desde que você respeite os termos da licença.

Temporalis, Brasília (DF), ano 19, n. 37, p. 151-171, jan./jun. 2019. | ISSN 2238-1856 


\begin{abstract}
The Social Service is a profession that historically was constituted under conservative bases. These have never ceased to permeate the formation and the professional exercise despite the advances made by the category, not being also an exclusivity of this profession, but own of the dynamics of reproduction of the capital. The advancement and re-visualization of this conservatism in society demands an urgent and indispensable reflection on its refutations for Social Work. Thus, the present study has as a general objective to understand the incisions of conservatism in professional training, having as a locus of research the Social Service course of Federal Institute of Education, Science and Technology of Ceará (IFCE) Campus Iguatu. The research, of qualitative character, used as methodological procedures bibliographical, documentary and field research, the latter carried out with students of the seventh and eighth semesters and which presented the following results: the students have a reasonable knowledge about conservatism and its forms of expression in the society and profession, conservatism has been expressed mainly from moralistic and prejudiced positions on the part of students and employees of the institution, in addition to the growth of conservative perspectives by the analysis of the professional vanguard. Regarding the corporate guidelines, the students interviewed are positioned, in the majority, in line with what has been pointed out the project of hegemonic profession in Social Service.
\end{abstract}

\title{
KEYWORDS
}

Social Service; Professional qualification; Conservatism.

Submetido em: 3/5/2018.

Revisto em: 29/1/2019.

Aceito em: 1/4/2019.

\section{INTRODUÇÃO}

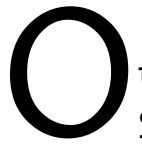

recrudescimento do conservadorismo no seio da profissão tensiona avanços teórico-políticos conquistados historicamente pela vanguarda mais crítica do Serviço Social. Este movimento de fortalecimento conservador não é endógeno e está associado à própria dinâmica atual das relações sociais, impostas pelo capitalismo e de suas formas de reprodução. Contudo, considerar as bases de constituição dessa profissão é imprescindível para compreender as incisões históricas do pensamento conservador para a formação e o exercício profissional, bem como os riscos de seu fortalecimento atual.

É bem verdade que esse conservadorismo nunca deixou de permear a profissão, se apresentando em alguns momentos de forma mais explícita e em outros de forma mais implícita, tendo seu fortalecimento sempre ancorado nas determinações societárias de cada tempo histórico (BOSCHETTI, 2015).

A atual conjuntura tem sido favorável para o crescimento e fortalecimento de grupos conservadores, de cunho políticos e religiosos que destilam todo tipo de preconceito, misoginia, racismo e a manutenção do status quo a partir do convencimento sem nenhum tipo de reflexão por parte das grandes parcelas da classe trabalhadoras. Aliado a isso, ganham força e adesão perspectivas teóricas que desconsideram a luta de classes, a dinâmica contraditória da sociabilidade capitalista e seus processos de reordenamento no mundo do trabalho para manter suas taxas de lucratividade diante das crises, além das análises acerca das expressões da "questão social" como fatos sociais isolados, tendo como foco de resolutividade a responsabilização dos indivíduos e da sociedade civil pela via da solidariedade.

Todos esses elementos vão incidir sobremaneira não só nas novas requisições feitas ao Serviço Social mas na forma como o conjunto de profissionais e estudantes percebem, analisam e intervém na realidade social. Assim, o interesse por estudar as implicações

Temporalis, Brasília (DF), ano 19, n. 37, p. 151-171, jan./jun. 2019. | ISSN 2238-1856 
dessas novas formas de expressão do conservadorismo para a formação profissional circunscreve-se no próprio crescimento de tendências e posturas conservadoras na sociedade, o que não imuniza os/as estudantes dos cursos de Serviço Social, bem como a fragilização dos espaços de formação frente ao crescente espraiamento indistinto dos cursos de Serviço Social no Brasil, e do sucateamento dos espaços públicos de formação.

Além disso, muitos dos traços conservadores presentes no exercício profissional estão diretamente ligados ao avanço desse pensamento na formação dos/as assistentes sociais através de elementos como a incorporação de linhas de pensamento acríticas nos currículos, o distanciamento de um rigor teórico, dado pela fragilização dos espaços de formação e das condições do trabalho docente.

Nesse sentido, o presente estudo tem como objetivo geral compreender as incisões do conservadorismo para a formação profissional em Serviço Social, tendo como campo de pesquisa o curso do Instituto Federal de Educação, Ciência e Tecnologia do Ceará (IFCE) Campus Iguatu e como objetivos específicos: analisar de que forma o conservadorismo é entendido pelos/as estudantes do curso; entender como esse conservadorismo se expressa no cotidiano do curso de Serviço Social do IFCE Campus Iguatu e perceber como os estudantes se posicionam diante de pautas societárias presentes no debate conservador do país.

Considerando a pesquisa como mediação privilegiada na relação entre conhecimento e realidade, é necessário entender que esta é a atividade basilar da ciência na construção da realidade. Nesse sentido, embora se utilize da teoria como objeto central, dialoga também com o pensamento e a ação, ou seja, "[...] nada pode ser intelectualmente um problema se não tiver sido, em primeiro lugar, um problema da vida prática” (MINAYO, 2010, p. 16).

Para alcançar os objetivos aqui elencados, nos debruçamos em um estudo analítico de base qualitativa que teve como meio de coleta de dados a utilização de questionário, aplicados aos/as estudantes dos semestres finais do curso de Serviço Social do IFCE Campus Iguatu, por entender que as informações obtidas através deste instrumento permitem observar determinadas características de um indivíduo ou de um grupo, podendo por sua vez, cumprir diversos objetivos (RICHARDSON, 2015). É ainda, um instrumento de coleta de dados constituído por uma série de perguntas, que devem ser respondidas por escrito (MARCONI; LAKATOS, 2000).

Para a participação na pesquisa foram escolhidos/as os/as estudantes de sétimo e oitavo semestres que estão matriculados na disciplina de Educação Popular, tendo em vista que estes já vivenciaram praticamente por completo seu processo formativo, o que pressupõe inclusive um maior amadurecimento teórico e apropriação da profissão e de suas bases de constituição.

O questionário foi aplicado no mês de dezembro de 2017, à dezoito estudantes que se dispuseram espontaneamente a participar da pesquisa e que estavam em sala de aula no dia da aplicação do questionário. A discussão pertinente à temática e os resultados obtidos estão dispostos de forma mais detalhada nos tópicos que se seguem e são a base para a produção deste trabalho. $\mathrm{O}$ artigo está dividido em quatro partes, conforme descrito a seguir: 
No primeiro tópico, intitulado O Conservadorismo e suas Bases de Constituição, abordamos a disseminação e consolidação do conservadorismo, apontando os seus elementos centrais e sua vinculação direta com o sistema de reprodução social do modo de produção capitalista. No segundo tópico, intitulado Conservadorismo e Serviço Social: elementos para pensar a formação profissional, elencamos a relação entre o conservadorismo e a trajetória histórica do Serviço Social e suas incisões na formação profissional. O terceiro tópico, denominado percurso metodológico trata da metodologia utilizada na pesquisa, das técnicas de coleta e análise dos cados.

No quarto ponto, O curso de Serviço Social do IFCE Campus Iguatu e o conservadorismo, uma análise a partir da percepção dos/as estudantes, buscamos apresentar os elementos encontrados a partir da pesquisa e pautar, diante disso, uma reflexão acerca dos impactos do conservadorismo na formação profissional do curso de Serviço Social do IFCE Campus Iguatu, bem como a percepção e o posicionamento dos/as estudantes em fase final de graduação acerca de pautas societárias presentes no debate conservador do país. Por fim forma feitas as considerações finais.

\section{O CONSERVADORISMO E SUAS BASES DE CONSTITUIÇÃO}

O pensamento conservador não está descolado das determinações sócio-históricas, tão pouco é atemporal e a-histórico. Suas bases de constituição estão ancoradas no processo de reprodução do capital, sendo elemento central para a conservação da sociabilidade capitalista, estando sempre à sua disposição (BOSCHETTI, 2015). Para garantir seu melhor entendimento é preciso considerar a sua funcionalidade a partir da consolidação do modo de produção capitalista como favorecedor da coesão e da neutralização das contradições fundamentais produzidas neste modelo de sociabilidade.

As primeiras manifestações do pensamento conservador se apresentam como uma resposta à Revolução Francesa e a consequente derrocada do feudalismo. Assim, inicialmente o conservadorismo defendia a manutenção do modo de funcionamento das relações sociais e institucionais solidificadas até o presente momento, sendo contra qualquer tipo de movimentação revolucionária da burguesia, tendo como pressuposto central a manutenção da tradição e dos costumes no antigo regime. Segundo Oliveira (2016),

[...] o pensamento conservador surge e se desenvolve no contexto da sociedade moderna, marcada e dinamizada pelas lutas de classes. As primeiras manifestações do pensamento conservador contrapõem-se aos princípios do Iluminismo, da Revolução Francesa, do liberalismo-burguês; de modo geral, recusa a modernidade e os elementos democratizantes que são constitutivos da dinâmica da sociedade moderna, marcada pela emancipação do homem da fé e da tradição (OLIVEIRA, 2016, p. 4).

Isso significa, segundo Santos (2007), uma aceitação apenas parcial do capitalismo, onde se reconhecia as vantagens tragas por tal modo de produção mas também a tentativa de convivência deste com instituições sociais pré-capitalistas, ou seja, o privilégio das famílias, da Igreja, a cristalização da hierarquia constituída socialmente, dentre outros, o que simboliza a negação do caráter revolucionário da revolução burguesa que, como portadora 
dos ideários da modernidade ia contra a ordem natural do universo. O pensamento conservador aqui expressa de forma central os interesses da nobreza e do alto clero.

A cultura moderna e "[...] seus traços mais determinantes - racionalismo, a autonomia individual, humanismo, historicismo - e suas características mais marcantes - secularização, dessacralização do mundo, valorização da experiência controlável e universalizante [...]" (ESCORSIM NETTO, 2011, p. 43, grifos da autora) mensurada aqui como contrariedade central do pensamento conservador, começa a perder sua funcionalidade a partir da configuração da burguesia como classe dominante.

Essa conversão da burguesia faz com que a mesma deixe de representar os interesses do conjunto da sociedade, a saber, daqueles/as inclusive que deram base para a tomada do poder contra o antigo regime e passe à defesa de seus interesses particulares, atribuindo à cultura moderna uma outra funcionalidade, tendo em vista que os interesse da classe que ascende passa a ser a defesa do status quo. Destarte,

\footnotetext{
Inicia-se, assim, por volta de 1830, um profundo e complexo movimento, ao fim do qual aquela cultura ver-se-á refuncionalizada para atender às exigências que agora se põem à burguesia - trata-se de uma refuncionalização que terá por objetivo eliminar ou neutralizar os conteúdos subversivos da cultura moderna, especialmente aqueles vinculados à sua dimensão emancipatória (ESCORSIM NETTO, 2011, p. 47, grifos da autora).
}

Se em sua origem o pensamento conservador se configura essencialmente como restaurador e antiburguês, a partir dos acontecimentos entre os anos de 1830 e 1848, que marcam essa nova tomada de posição ideológica da burguesia e o acirramento de suas contradições, o desenvolvimento do capitalismo e as forças organizativas engendradas pelo movimento operário, faz com que esse pensamento passe a operar uma repulsa a qualquer forma revolucionária ou de questionamento da ordem vigente, tendo “[...] substantivamente mudada sua função social: de instrumento ideal de luta antiburguesa, converte-se em subsidiário da defesa burguesa contra o novo protagonista revolucionário, o proletariado" (ESCORSIM NETTO, 2011, p. 49-50).

Segundo lamamoto (2011) esse conservadorismo moderno é fruto, portanto, de um momento histórico específico, a sociedade de classe onde a burguesia tem sua emergência como protagonista do mundo capitalista, onde a mercadoria passa a mediar as relações sociais e o lucro. Nesse sentido, o pensamento conservador tem sua fonte de inspiração no modo de vida do passado que é resgatado no sentido de interpretar o presente e manter viável o programa da sociabilidade capitalista. Em seus termos:

O conservadorismo não é assim apenas a continuidade e persistência no tempo de um conjunto de ideias constitutivas da herança intelectual Europeia do século $\mathrm{XIX}$, mas de ideias que, reinterpretadas, transmutam-se em uma ótica de explicação e em projetos de ação favoráveis à manutenção da ordem capitalista. Isso aproxima os pensamentos conservador e racional, apesar de suas diferenças, como portadores de um mesmo projeto de classe para a sociedade (IAMAMOTO, 2011, p. 23).

Tais transformação vão incidir tanto na função sociopolítica do conservadorismo, agora aliada aos componentes culturais da ordem burguesa, como em seus pressupostos teóricoconceituais, que frente ao crescimento do antagonismo entre as classes fundamentais, faz com que os conservadores busquem a conciliação entre o progresso e a ordem social (SANTOS, 2007) e nesse sentido o positivismo se configura como um componente

Temporalis, Brasília (DF), ano 19, n. 37, p. 151-171, jan./jun. 2019. | ISSN 2238-1856 
importante, não só do ponto de vista da tomada de direção política e social da burguesia, mas na construção de um conhecimento que favoreça a sua manutenção e o seu caráter reformista.

Segundo lamamoto (2011) as características do conservadorismo que tomam maior destaque são: a sua vocação para o passado, que é experimentado como presente; o entendimento da sociedade como constituída de entidades orgânicas e coesas como a família; os elementos sagrados e irracloionais são extremamente valorizados e utilizados em detrimento da razão; a tradição e o costume passam a legitimar a sociedade; a individualidade é radicalizada; a liberdade é limitada à constituição da habilidade de cada indivíduo de desenvolver-se de acordo com as limitações e possibilidades de sua personalidade.

A autora aponta ainda que o conservador tende sempre a valorizar os detalhes, os casos particulares em detrimento da apreensão da estrutura da sociedade a partir de uma perspectiva de totalidade. E ainda:

\begin{abstract}
A mentalidade conservadora não possui predisposição para teorizar. Sendo a organização da sociedade vista como fruto de uma ordenação natural do mundo, o conhecimento visa a um controle prático das situações presentes. O conservador elabora seu pensamento como reação a circunstâncias históricas e ideias que se afiguram ameaçadoras à sua influência na sociedade. $O$ conservadorismo torna-se consciente, no plano da reflexão, como defesa, decorrente da necessidade de armar-se ideologicamente para enfrentar o embate das forças oponentes (IAMAMOTO, 2011, p. 24).
\end{abstract}

Cabe salientar que a solidificação de tal pensamento deita suas raízes nas próprias características das relações sociais, estabelecidas a partir da necessidade e dinâmica de cada tempo histórico, onde vão se formando os valores, a cultura e a moralidade. É sobre estas bases que se assentam as formas de socialização dos indivíduos e seu comportamento, bem como suas concepções daquilo que é certo ou errado. Assim, a inserção do pensamento conservador e sua naturalização no cotidiano das relações sociais torna-se imprescindível para a reprodução da força de trabalho no modo de produção capitalista e de suas bases ideológicas de constituição.

As mudanças ocorridas a partir dos anos de 1970 oriundas da crise do modelo fordista/keynesiano, do processo de restruturação produtiva com o fortalecimento do capital financeiro e da mundialização do capita constituíram as bases para a emersão de novos pressupostos sociais e de uma onda conservadora, ancorada pelos ideários do neoliberalismo, que afetou diretamente não só os fundamentos do pensamento e da intelectualidade mundial mas também das condições de vida das massas trabalhadoras, dando ao pensamento conservador um fôlego inesperado.

A retomada do crescimento econômico a partir da quebra do ciclo de produção/ consumo tido até então é pretendida a partir de três frentes: no aumento da área de aplicação do capital especulativo, apoiado na liquidez e capacidade de mobilidade deste; na reestruturação industrial a partir do aumento da concorrência combinado à flexibilização da produção desde o estabelecimento de uma nova organização do trabalho e do investimento em inovações tecnológicas e organizacionais; na transformação na esfera estatal com o aumento da liberdade do capital, principalmente financeiro, na garantia de

Temporalis, Brasília (DF), ano 19, n. 37, p. 151-171, jan./jun. 2019. | ISSN 2238-1856 
condições propícias à extração de mais-valia e na desregulamentação das economias e dos direitos da classe trabalhadora, tendo como base de sustentação o neoliberalismo (SANTOS, 2007).

Dessa forma, as transformações estruturais ocorridas no interior do capitalismo contemporâneo, apontadas principalmente pelo processo de mundialização e financeirização do capital, aliadas às mudanças culturais e aos acontecimentos políticos, sobretudo pela derrocada do chamado socialismo real, geraram um certo descrédito aos projetos revolucionários e a seus defensores. Todo esse processo viabilizou a expansão e adesão de perspectivas e formulações ídeo-teóricas que reatualizam o pensamento conservador, ainda que sobre novas bases, e o colocam na ordem do dia. É importante considerar que:

\begin{abstract}
O conservadorismo contemporâneo apresenta inúmeros traços de que carece o conservadorismo 'clássico' - e são tantos, que fazem da constelação conservadora atual algo bastante diverso daquela do século XIX. A característica mais imediata do conservadorismo contemporâneo [...] consiste em que ele não se apresenta como conservadorismo e, portanto, oculta e escamoteia sua raíz e seus conteúdos conservadores [...] Da mesma maneira que o conservadorismo 'clássico' mudou de função depois das revoluções de 1848, o conservadorismo do século $\mathrm{XX}$ mudou de função nos últimos trinta anos, e esta mudança afetou inclusive a sua forma social (ESCORSIM NETTO, 2011, p. 16-17, grifos da autora).
\end{abstract}

Para Boschetti (2015), o avanço do conservadorismo nas últimas décadas se apresenta em diversos campos da sociedade, fortalecido por determinações societárias de cunho econômico, social e ídeo-cultural. No campo econômico, a crise do capital faz ressurgir políticas, medidas e valores conservadores a partir da apologia ao livre mercado, na redução do papel do Estado na regulamentação da economia e dos direitos sociais, no uso dos recursos públicos para salvar as empresas e bancos em tempos de crise e na mercantilização dos serviços e políticas sociais. Em curso, na conjuntura mundial, a partir dos anos de 1970 tais movimentações alimentam o individualismo, a competitividade e os valores liberais conservadores.

No campo social, a partir do desmonte de um Estado interventor, do qual foram exemplos os países da Europa central, intensifica a precarização do trabalho, a agudização das desigualdades sociais e a perca de direitos sociais na educação, saúde aposentadoria, transporte e moradia. Para o campo ídeo-cultural, prevalecem o avanço do fundamentalismo religioso, principalmente como crescimento de vertentes neopentecostais, o acirramento da intolerância e o crescimento das mais variadas formas de opressão e preconceito. Em contrapartida, crescem também as formas de organização e resistência por parte dos grupos sociais historicamente oprimidos, sobretudo, setores de mulheres, negros/as, LGBT's e juventudes (BOSCHETTI, 2015).

Os elementos até aqui apresentados são determinantes para o alargamento do conservadorismo e seu entendimento é imprescindível para a construção de alternativas de reflexão e intervenção para o Serviço Social, tendo em vista que o avanço ou a reatualização do conservadorismo não é apenas algo externo à formação e ao trabalho dos/as assistentes sociais. Ao contrário, as últimas mudanças na tecitura social vão reverberar diretamente na configuração da profissão, nas demandas que nos são 
apresentadas no cotidiano, na formulação de nossas estratégias de trabalho e formação, bem como nas nossas condições para exercê-las.

No tópico seguinte, abordaremos a relação entre conservadorismo e Serviço Social e suas incidências na construção da formação profissional.

\title{
CONSERVADORISMO E SERVIÇO SOCIAL: ELEMENTOS PARA PENSAR A FORMAÇÃO PROFISSIONAL
}

O Serviço Social é uma profissão instituída em tempo histórico específico, situado no desenvolvimento do capitalismo em sua fase monopolista, sendo designada para dar respostas às expressões da "questão social" frente ao acirramento da luta de classes, proveniente do desenvolvimento das forças produtivas e precarização das condições de vida e trabalho do proletariado. Assim, “[...] trata-se de uma profissão que, historicamente, tem sido requisitada tanto na esfera privada quanto pública para esvaziar o conteúdo político e econômico das expressões da 'questão social' para reenquadrá-las ou minimizálas" (ORTIZ, 2010, p. 140).

As primeiras formas de intervenção no Brasil, vinculadas a um projeto reformistaconservador, situam-se em meados dos anos de 1930 e tinham como base ideológica a doutrina social da Igreja Católica, onde foram desenvolvidos seus primeiros núcleos formativos, e o positivismo, em um processo que se configurou como um arranjo teóricodoutrinário (IAMAMOTO, 2011). Eminentemente conservadores tais pressupostos visavam o ajustamento moral da classe trabalhadora a partir da individualização dos problemas sociais e da mudança de comportamento dos sujeitos. Portanto,

\begin{abstract}
A presença do conservadorismo moral, no contexto de origem do Serviço Social é evidenciada: na formação profissional, no projeto social da Igreja Católica e na cultura brasileira, através das ideias positivistas. A vivência cotidiana, orientada por seus pressupostos valorativos, tende a reproduzir a alienação moral, em seus aspectos já assinalados: a repetição a-crítica dos valores, a assimilação rígida dos preceitos e modos de comportamentos, o pensamento ultrageneralizador, o preconceito, o conformismo, a discriminação, tendo em vista a não aceitação do que não se adequa aos padrões de comportamento estereotipados como 'corretos' (BARROCO, 2001, p. 74 apud BONFIM, 2015, p. 111-112).
\end{abstract}

A junção dessas perspectivas de análise e percepção da realidade social permitem que os efeitos da exploração do capital sejam percebidos, entretanto, sem colocar em questão as razões históricas dessa exploração, o que permite conciliar a concepção humanista-cristã e a exploração burguesa do trabalho. São empreendidos esforços na perspectiva de solidariedade entre as classes, visto que a condição comum de serem humanos superaria qualquer diferença social, sendo a solução para qualquer problemática a reforma do homem dentro da sociedade, onde o Serviço Social deveria contribuir (IAMAMOTO, 2011). Ainda segundo a autora,

Trata-se de um trabalho 'educativo' entre a família operária, especialmente entre os mais carentes que têm acesso aos equipamentos sócio-assistenciais, com o objetivo de reforçar o núcleo familiar e integrar seus membros à sociedade. Buscam-se na história familiar os elementos explicativos de comportamento individuais 'anômalos' ou 'desviantes' de um padrão tido como ‘normal'. A família, como grupo social básico, é erigida como núcleo do trabalho profissional e como

Temporalis, Brasília (DF), ano 19, n. 37, p. 151-171, jan./jun. 2019. | ISSN 2238-1856 
referência para a apreensão da vida em sociedade, em contrapartida às classes sociais (IAMAMOTO, 2011, p. 29).

Outro elemento que corrobora com o funcional conservadorismo enraizado no discurso e na prática profissional historicamente constituída é o próprio perfil requisitado para a admissão nos primeiros centros de formação, que imprimirá ao Serviço Social uma determinada imagem social vinculada ao cuidado e à ajuda. Tratando-se de uma profissão majoritariamente escolhida e desenvolvida por mulheres, a partir do entendimento que estas possuíam as qualidades natas para as tarefas educativas e caridosas, sendo representantes da moral e dos bons costumes, exercendo sem qualquer pretensão particular o bem a partir do bom desempenho de suas atividades.

A prioridade da vocação, portanto, era um requisito de ingresso na profissão, sendo esta uma característica que, segundo Ortiz (2010) contribuirá para a construção de um determinado ethos profissional que abriga consequências até hoje, como por exemplo, a dificuldade de apreender qual o lugar que ocupa a teoria no exercício profissional, pois sendo uma profissão cujo critério de ingresso de baseava em valores morais e pessoais tornava-se secundária a apreensão dos conhecimentos teóricos.

Netto (2009) reitera ainda que a gestação da profissão sob uma perspectiva conservadora se assenta em dois traços que dentre outros, podem ser apontados como centrais. Primeiro, a configuração de uma profissão da prática, inserida na divisão sociotécnica do trabalho para dar respostas conservadoras às expressões da "questão social" e em segundo lugar, o caráter subalterno às Ciências Sociais, se constituindo como operativa, pragmática, avessa às formulações de conhecimento e amparadas pelas teorias mais conservadoras.

A reação a essa herança conservadora começa a se gestar a partir do Movimento de Reconceituação ${ }^{1}$ na América Latina e ganhou expressividade no Brasil a partir da década de 1960 por meio da vertente denominada de intenção de ruptura, ganhando veemência na década de 1970. Sua efetivação só é possível a partir da incorporação da teoria marxista no âmbito da produção de conhecimento do Serviço Social, pelo compromisso assumido pela categoria com a classe trabalhadora, a partir de sua vinculação aos movimentos sociais e partidos políticos anticapitalistas, pelo confronto crítico de ideias, valores e princípio que começaram a questionar a direção conservadora que norteava a formação e o exercício profissional. Além disso, tal ruptura só foi possível pela construção de uma direção teóricopolítica através das entidades representativas da profissão (NETTO, 2009).

Constituiu-se, portanto, a partir desses aspectos, uma direção hegemônica em torno de um Projeto Ético-Político vinculado aos interesses da classe trabalhadora, que considera a dinamicidade e contraditoriedade do modo de produção capitalista e aponta para uma nova forma de sociabilidade, livre de todas as formas de opressão, preconceito e exploração o que, entretanto, não nos permite afirmar que foi superada a presença do

\footnotetext{
${ }^{1}$ O movimento de Reconceituação sucedeu-se em nível de América Latina, datado historicamente dos anos de 1965 a 1975 congregando diferentes correntes de pensamentos que tentavam romper com a introjeção da perspectiva do Serviço Social Norte Americano na América Latina. Segundo Netto (2011) a Reconceituação "[...] está intimamente vinculada ao circuito sociopolítico latino-americano da década de sessenta: a questão que originalmente a comanda é a funcionalidade profissional na superação do subdesenvolvimento" (NETTO, 2011, p. 146, grifos do autor).
}

Temporalis, Brasília (DF), ano 19, n. 37, p. 151-171, jan./jun. 2019. | ISSN 2238-1856 
conservadorismo na profissão, tendo em vista que a mesma se desenvolve e materializa nas relações cotidianas que são alimentadas por determinações sociais fundadas no próprio pensamento conservador. Dessa forma,

\begin{abstract}
Se considerarmos ainda a conjuntura brasileira na atualidade, veremos que essas determinações são decisivas para a reatualização de valores conservadores na profissão. Isso significa afirmar que, embora se reconheça a importância de um referencial teórico-metodológico crítico para o questionamento dos valores dominantes na sociedade e na profissão, isso não é o suficiente para o rompimento de tais valores (BONFIM, 2015, p. 138).
\end{abstract}

São evidentes os avanços alcançados a partir da apropriação de um referencial teórico crítico pela profissão, que possibilitou uma melhor reflexão acerca dos fundamentos da ética e das possibilidades e entraves na realização do exercício profissional em seu cotidiano. Contudo, os obstáculos postos pela sociabilidade burguesa para a realização de uma ética emancipadora, somados aos elementos próprios da particularidade da formação sócio-histórica do Brasil, acabam por contribuírem para que haja um predomínio de uma moralidade conservadora no país (BONFIM, 2015).

Os traços indicativos de uma reatualização do conservadorismo não podem ser compreendidos como característica particular ao Serviço Social, mas como uma tendência presente no conjunto das relações sociais capitalistas, alimentadas pelo processo de mundialização e financeirização do capital, da sujeição dos países de economia periférica às recomendações dos organismos internacionais e da refuncionalização do Estado, balizada pelo neoliberalismo ${ }^{2}$ e sua política de desregulamentação do mercado de trabalho e dos direitos sociais (BOSCHETTI, 2015). Assim, o atual padrão mundial de acumulação reduz a oferta de empregos formais, valoriza a competição, o individualismo, cria um ambiente de profunda instabilidade e insegurança, além de estimular a incidência de preconceitos sociais, religiosos, étnicos, diferentes formas de racismo, messianismo e xenofobia (SANTOS, 2007).

Todo esse cenário de desmonte vai incidir demasiadamente não só no exercício profissional em Serviço Social e na precarização das condições e dos espaços de trabalho, mas também na formação profissional, a partir da sua privatização, com ênfase para o ensino à distância (EAD), da fragilização das suas condições de materialização, do sucateamento dos espaços públicos, da precarização da condição do trabalho docente, bem como a não viabilização de espaços de pesquisa e extensão, e da vivência de espaços políticos de organização, o que destoa daquilo que hegemonicamente foi constituído como perspectiva formativa para os/as assistentes sociais.

Para a perspectiva crítica a formação profissional não pode se reduzir à mera oferta de disciplinas a fim de obter uma titulação e responder às demandas postas ao mercado de

\footnotetext{
${ }^{2}$ Pode-se entender o neoliberalismo por uma reação teórica e política contra o Estado intervencionista, como forma de superação da estagnação econômica do fim dos denominados anos de ouro do capital. A partir de 1980 a maior parte dos governos passaram a assumir os ideários desse tipo de governo que possibilitava a flexibilização e globalização política e econômica, a redução por parte do Estado nos investimentos sociais, o retrocesso dos movimentos sindicais, bem como o aumento do desemprego, a privatização de serviços e, sobretudo empresas estatais, e o retrocesso de grande parte dos direitos alcançados pelos/as trabalhadores/as (MOREIRA; OLIVEIRA; ALBUQUERQUE, 2013, p. 703-704).
}

Temporalis, Brasília (DF), ano 19, n. 37, p. 151-171, jan./jun. 2019. | ISSN 2238-1856 
trabalho, mas além disso, "[...] trata-se de preparar cientificamente quadros profissionais capazes de responder às exigências de um projeto profissional coletivamente constituído e historicamente situado" (IAMAMOTO, 2011, p. 163).

O tema da formação tem sido objeto de inúmeras reflexões no Serviço Social, tendo em vista que, segundo Netto (2009), o próprio avanço do conservadorismo presente no exercício profissional está diretamente relacionado com o avanço de certos traços conservadores em seu âmbito, principalmente a partir da mercantilização dos espaços de formação, do aligeiramento desses processos e do afastamento da perspectiva crítica, o que confronta as próprias Diretrizes Curriculares da Associação Brasileira de Ensino e Pesquisa em Serviço Social (ABEPSS) de 1996.

Outro elemento que não pode ser desconsiderado e que ultrapassa as condições objetivas da formação profissional oferecida são as formas de apreensão feita pelos/as estudantes, cabendo salientar que, a formação profissional posta aos indivíduos pode problematizar determinados elementos que forjem uma maior criticidade. Entretanto, não significa dizer que porque a formação tem uma fundamentação histórico-crítica de análise da realidade, esses sujeitos necessariamente farão essas apreensões, tendo em vista que mesmo sendo portadores de uma sociabilidade, de um projeto societário, estes indivíduos também são expressões singulares, que carregam valores particulares, visões de mundo, crenças e vivências individuais. Como nos aponta Barroco (2001):

\footnotetext{
Dada a complexidade da totalidade sócio-histórica, os valores não operam da mesma forma em cada esfera social [...] O indivíduo é ao mesmo tempo, enquanto portador do ser social, um ser genérico e uma expressão singular [...] Esse processo é movido por mediações que operam tanto no sentido de afirmação das capacidades essenciais do ser social, quanto no de sua negação. Disso decorre a dinâmica da história, evidenciando um desenvolvimento desigual, extensiva e intensivamente, o que significa afirmar que as objetivações humano-genéricas não são apropriadas por todos os indivíduos, em toda a história e, em cada momento específico, nas diversas esferas (BARROCO, 2001, p. 32).
}

Dessa forma, fazem-se necessárias investigações que se proponham a elucidar questões referentes às formas de materialização do conservadorismo na formação profissional em Serviço Social, não somente do ponto de vista da disposição dos projetos pedagógicos dos cursos, mas como este pensamento tem se materializado no cotidiano dos/as estudantes desses cursos, como algumas questões centrais que diretamente envolvem 0 conservadorismo tem sido pautadas e a partir disso, quais os processos de síntese e apreensão da realidade tem sido feitas pelos estudantes.

O presente estudo se propôs a investigar a realidade do curso de Serviço Social do IFCE Campus Iguatu, considerando inclusive seu caráter de pioneirismo na rede dos Institutos Federais. Outro elemento que não pode ser desconsiderado é o próprio histórico tecnicista apresentado pela instituição, o que coloca para um curso como o Serviço Social uma série de desafios para a consolidação de uma formação crítica, com perspectiva de totalidade e comprometida com a transformação social. 


\section{O CURSO DE SERVIÇO SOCIAL DO IFCE CAMPUS IGUATU E O CONSERVADORISMO: UMA ANÁLISE A PARTIR DA PERCEPÇÃO DOS/AS ESTUDANTES}

O curso de Serviço Social do Instituto Federal de Educação, Ciência e Tecnologia foi criado a partir da Resolução $n^{\circ}$ 023, de 31 de maio de 2010 e é o segundo curso público do estado do Ceará. Com sete anos de funcionamento, o curso tem 183 estudantes matriculados, sendo 112 do sexo feminino e 71 do sexo masculino. Oferta 35 vagas semestrais e tem como forma de ingresso a utilização da nota do Exame Nacional do Ensino Médio (ENEM) por meio do Sistema de Seleção Unificada (SISU) e uma média de 15 vagas disponíveis para o processo seletivo por edital para o ingresso de graduados e transferências internas e externas.

Está estruturado em oito semestres letivos, 3.610 horas/aula, sendo 2.840 horas para disciplinas obrigatórias, 160 para disciplinas optativas, 160 para atividades complementares e 450 destinadas ao estágio supervisionado, tendo ainda uma carga horária de 160 horas para a construção do Trabalho de Conclusão de Curso (Relatório do Departamento de Registro Acadêmico, 2017).

A pesquisa se direcionou as/aos estudantes dos semestres finais da graduação a fim de perceber as incisões do conservadorismo no processo de formação e no cotidiano do curso, bem como, apreender os elementos de entendimentos dessas/es alunos acerca da temática. Dos/as dezoito entrevistados/as, doze estão regularmente matriculados/as no sétimo período e seis no oitavo período. Sobre suas identidades de gênero, quinze se declararam mulheres cis $^{3}$, dois homens cis e um/a entrevistado/a não respondeu ao item, o que nos aponta o fato de ser um grupo majoritariamente feminino, característica preponderante em todo o curso.

Todos estão numa faixa etária de 22 a 40 anos sendo que doze destes possuem entre 22 e 25 anos, o que mostra ser um alunado jovem. São naturais das cidades de Fortaleza, Acopiara, Aiuaba. Iguatu, Várzea Alegre, Jucás, Lavras da Mangabeira, Cedro e Orós, todas localizadas no Ceará e Guarulhos (SP), o que demonstra que a grande maioria dos/as entrevistados/as são provenientes de cidades de pequeno e médio porte, localizadas no interior.

Quando questionados/as acerca do que seria o conservadorismo, as respostas se deram majoritariamente situando o conservadorismo no campo da manutenção de valores e práticas estáticas, que impedem qualquer mudança, sempre vinculadas às relações sociais no capitalismo e sua reprodução, como se pode ver nas falas dos/as entrevistados/as:

É uma política de direita que defende interesses capitalistas (Entrevistado/a 15).

São processos presentes nas relações sociais, as quais são dirigidas por um sistema opressor e desigual em suas estruturas (Entrevistado/a 02).

São práticas vinculadas ao passado, que já deviam ter sido superadas (Entrevistado/a 03).

\footnotetext{
${ }^{3} \mathrm{CIS}$ - abreviatura de CISGÊNERO, é a terminologia utilizada para designar pessoas que se identificam com o gênero que lhes foi designado no nascimento. Aqueles/as que não se identificam com o gênero que lhe fora atribuído no nascimento são denominados como TRANSGÊNEROS.
}

Temporalis, Brasília (DF), ano 19, n. 37, p. 151-171, jan./jun. 2019. | ISSN 2238-1856 
Respostas que demostram entendimento superficial, que pode ser um apontamento para a falta de profundidade dessas discussões durante a graduação. Um elemento importante nesse quesito e que deve ser considerado é o fato de cinco dos/as entrevistados/as associaram diretamente o conservadorismo ao Serviço Social, não elencando nenhum elemento de uma discussão mais geral, associando portanto o conservadorismo somente aos processos do Serviço Social e sua constituição enquanto profissão, como se pode observar:

\begin{abstract}
Seria a renovação de práticas na profissão em sua gênese. Já que após o processo de tentativa de ruptura com práticas conservadoras, que envolve a psicologização da "questão social" e sua naturalização (Entrevistado/a 13).

O curso de Serviço Social passou por um processo de reformulação da base teórica, sendo hoje colocada por Marx, mais crítico, mas o problema é que muitos profissionais não conseguem atingir essa dimensão, desrespeitando o projeto ético-político da profissão, expondo assim práticas preconceituosas, reacionárias e conservadoras (Entrevistado/a 06).
\end{abstract}

A pesquisa demonstrou como o conservadorismo é associado diretamente à profissão, sobretudo em sua relação com a Doutrina Social da Igreja e nas disciplinas ligadas aos Fundamentos da profissão. Pelo que foi exposto, o entendimento do conservadorismo como a matéria constituinte da disseminação dos preconceitos e intolerâncias na contemporaneidade não tem sido aprofundado, sendo apenas mensurado em algumas disciplinas como Relações de Gênero, Classe e Raça/etnia e Classes e Movimentos Sociais.

Além disso, um/a dos/as entrevistados/as não respondeu ao quesito e outro/a afirmou não ter propriedade para discorrer sobre o assunto, o que nos aponta a necessidade de discutir mais a fundo nos espaços de formação profissional o conservadorismo e sua relação com a sociedade e o Serviço Social.

Com relação à materialidade desse conservadorismo na contemporaneidade, os/as entrevistados/as situaram suas respostas, majoritariamente, no avanço de práticas preconceituosas, que não respeitam às diferenças, no avanço de posturas profissionais individualizadas, policialescas, no avanço de políticas fragmentadas, que não reconhecem os usuários como sujeitos de direito e no crescimento da filantropia. Alguns dos fragmentos nos demonstram tais afirmativas:

Nos discursos de ódio disseminados contra 'as minorias', contra os setores mais criminalizados da sociedade (mulheres, negros/as, LGBT's). Nos retrocessos das garantias de direitos já conquistados, nas posturas autoritárias e conservadoras que ainda existem nas diversas esferas da sociedade (Entrevistado/a 16).

Na dimensão do não entendimento da pessoa enquanto sujeito de direito, obtendo uma visão positivista do sujeito, culpabilizando-o de diversas formas (Entrevistado/a 06).

Por meio de programas sociais que colocam o indivíduo numa posição de que ele é o responsável pela situação que se encontra. Pela fiscalização da vida dos usuários (Entrevistado/a 17).

Outro aspecto mensurado nas entrevistas foi a materialização do conservadorismo a partir do crescimento de correntes teóricas como a pós-modernidade, como se pode observar: 


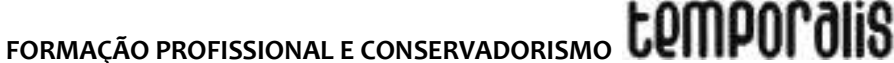

Nos preconceitos, em muitos discursos religiosos, no espraiamento da pósmodernidade e no aumento de julgamentos morais e subjetivos na sociedade (Entrevistado/a 01).

O conservadorismo na atualidade pode ser detectado com traços das concepções pós-modernas, que por vezes faz com que a profissão tenha algumas ideias conservadoras (Entrevistado/a 11).

Nas concepções pós-modernas, fazendo com que as pessoas tenham uma visão ainda menos crítica sobre as coisas (Entrevistado/a 07).

Quinze dos/as entrevistados/as afirmaram que o conservadorismo está presente no cotidiano do curso de Serviço Social do IFCE Campus Iguatu a partir das próprias posturas dos/as estudantes, situando principalmente o fundamentalismo religioso e moralismo presente nos discursos, também a partir de alguns docentes e suas posturas, além da própria natureza da instituição, considerada em algumas falas como conservadora. Em duas entrevistas foi apontado que não há presença do conservadorismo no curso e um/a entrevistado/a não respondeu ao quesito.

No questionário foram elencados algumas temáticas e pautas societárias que envolvem o conservadorismo a fim de que os/as estudantes expressassem seu entendimento. Pela relevância e atualidade foram escolhidos os temas do ensino religioso nas escolas, o tratamento de reversão sexual 4 , a legalização do aborto e a redução da maioridade penal.

Acerca do entendimento sobre a instituição do ensino religioso nas escolas, quinze entrevistados/as se colocaram contra, argumentando na grande maioria das respostas que a escola precisa ser laica, que a religiosidade pode ser desenvolvida em outros espaços e que a sua institucionalização geralmente é direcionada apenas a uma ou duas vertentes religiosas, o que desconsidera sobretudo àquelas de matrizes africanas e afins, como se pode observar nas seguintes falas:

A realidade que vivenciamos é que por ser o Brasil hegemonicamente um país católico, na realidade o que acontece no ensino religioso é a imposição e o ensinamento de uma única religião, no caso a católica. O que deveria ser o contrário pois já que existe uma série de crenças, manifestações de religião e fé, se fosse para haver ensino religioso nas escolas, que pudesse trazer a diversidade existente em nosso país e não uma única (Entrevistado/a 03).

Porque o direcionamento acaba por ser muito subjetivo a partir de quem ministra as disciplinas e acabam por abordar apenas uma religião (Entrevistado/a 01).

Os/as entrevistados que se colocaram a favor do ensino religioso se posicionaram, entretanto, pelo tratamento das mais diversas vertentes durante o ensino, como se pode perceber:

\footnotetext{
${ }^{4}$ Em 2017 essa discussão ganhou amplitude com a ação movida pela psicóloga Rozangela Alves Justino, e após o juiz federal da $14^{\mathrm{a}}$ Vara do Distrito Federal Waldemar Cláudio de Carvalho concedeu uma liminar que aprovada a aplicação da terapia de reversão sexual, pratica totalmente contraria ao que preconiza a Resolução 01/99_do Conselho Federal de Psicologia (CFP), que proibe qualquer tentativa de "cura das homossexualidades" por psicólogos. Outro elemento que permeia essa discussão da "cura gay" é o projeto de lei em discussão é o 4931 de 2016, apresentado por Ezequiel Teixeira (PTN-RJ).
} 
Sou a favor desde que não seja uma única religião estudada, mas que todas as religiões sejam compreendidas a fim de que os estudantes possam escolher livremente suas crenças (Entrevistado/a 13).

Sobre essa temática o conjunto CFESS/CRESS têm se posicionado a favor do fortalecimento e manutenção da laicidade do Estado e dentro disso, de todas as políticas públicas, dentre elas a educação, por entender que a laicidade do Estado é um pressuposto da democracia, por sua compatibilidade com a direção ético-política da profissão e por ser uma das formas de assegurar direitos e liberdades e no enfrentamento ao avanço do conservadorismo, expresso através de intolerâncias, discriminações e crimes de ódio (CONSELHO FEDERAL DE SERVIÇO SOCIAL, 2016). Assim,

As ameaças ao Estado Laico configuram-se como expressões do avanço do conservadorismo e do irracionalismo neste contexto de agudização dos antagonismos de classe e, consequentemente, uma ameaça ao processo de democratização da sociedade e do Estado brasileiros (CONSELHO FEDERAL DE SERVIÇO SOCIAL, 2016, não paginado).

Acerca do tratamento de reversão sexual, dezessete entrevistados/as se posicionaram contra, utilizando como base argumentativa a não possibilidade de reversão da orientação sexual e de esta não se configurar como uma doença, que necessita de tratamento. Apenas um/a entrevistado/a se colocou à favor do tratamento, sob o seguinte argumento:

Pois cada um sabe do seu corpo, e de como se sente bem, então acredito que se alguém opta por esse tratamento é porque está infeliz com a sua realidade (Entrevistado/a 10).

O Conselho Federal de Psicologia se posicionou sobre a temática, repudiando a Resolução 01/99 que prevê o tratamento de reversão sexual, entendendo que em um país como o Brasil, com altos índices de assassinatos por orientação sexual e identidade de gênero, não cabe à profissão a produção de mais violência e sofrimento a essa população já tão estigmatizada socialmente, se negando a ser "[...] um instrumento de promoção do sofrimento, do preconceito, da intolerância e da exclusão5".

Com relação à legalização do aborto, quinze entrevistados/as se colocaram à favor, dois/uas afirmaram não ter condição de se posicionar e uma pessoa se colocou contra, como se pode exemplificar nas falas abaixo:

A luta pela legalização do aborto é a luta pela vida das mulheres, por entender que cabe a elas decidirem sobre seu corpo e suas vidas (Entrevistado/a 01).

Sou contra porque deve-se prevenir com uma educação sexual eficaz, seria melhor do que criar um monte de leis que não funcionam (Entrevistado/a 12).

Ainda não posso me posicionar nem totalmente a favor e nem contra, pois para mim existem casos e casos. Mas entendo que no exercício da profissão não poderei deixar os meus princípios pessoais intervirem na minha prática (Entrevistado/a 10).

\footnotetext{
${ }^{5}$ Nota do Conselho Federal de Psicologia (2018).
} 
O aborto é uma realidade comum desde os tempos mais antigos até a atualidade e sua criminalização atinge consubstancialmente as mulheres pobres, tendo em vista que aquelas que possuem uma melhor condição socioeconômica recorrem ao aborto em clínicas que oferecem total qualidade no seu atendimento (BRAGA; MESQUITA; MATOS, 2013).

Esses aspectos demonstram a falta de abertura à discussão dessa temática, subsidiada na maior parte das vezes pelo fundamentalismo religioso que têm subsidiado a criminalização das mulheres que praticam o aborto, em detrimento da negligência sofrida tantas vezes nos espaços públicos de saúde quando essa mulher precisa de atendimento pós abortamento e, sobretudo, que tem cerceado o direito e a liberdade dessas mulheres sobre seus corpos. Já há algum tempo a categoria vem se posicionando a favor da luta da legalização do aborto e da não criminalização das mulheres, entendendo que para além dos valores morais essa é uma questão de saúde pública. Assim,

Reconhecendo todas as dimensões que envolvem a questão do aborto, na compreensão de que é a mulher que define pela interrupção (ou não) da gravidez (que sempre se dá num contexto complexo) e esta mulher tem o direito a um atendimento de qualidade, humanizado e de respeito, é que o Conjunto CFESS/CRESS defende, desde 2009, a descriminalização do aborto, e desde 2010, a legalização do aborto no Brasil. Tais posicionamentos foram deliberados coletivamente por assistentes sociais, representando todas as regiões do país, nos Encontros Nacionais da categoria (CONSELHO FEDERAL DE SERVIÇO SOCIAL, 2011, não paginado).

Sobre a redução da maioridade penal, foi unânime entre todos os entrevistados o posicionamento contrário à medida, como se pode ver nas seguintes afirmações:

Os índices comprovam que os atos infracionais cometidos por adolescentes não são muitos, eles morrem mais pela criminalização da juventude, principalmente negra e periférica. Uma juventude que tem diariamente seus direitos básicos (como lazer, educação, moradia digna) violados (Entrevistado/a 18).

Reduzir a maioridade penal não resolve o problema da violência, pelo contrário, vai agravar o problema. Políticas sociais e de acesso desses jovens a uma vida digna, com todos os seus direitos garantidos seria a solução (Entrevistado/a 15).

O CFESS também “[...] mantém seu posicionamento contrário à redução da maioridade penal e ao aumento do tempo de internação conjuntamente com os Movimentos Sociais, Conselhos de Direitos e Fóruns comprometidos com a questão da criança e adolescente no Brasil" (CONSELHO FEDERAL DE SERVIÇO SOCIAL, 2015) ${ }^{6}$. Ainda,

Estado e sociedade não podem ceder e/ou propalar apelos e interpretações que, equivocadamente, remetem a adolescentes e jovens a responsabilidade pela escalada da violência na sociedade. Significa ceder a uma visão social de mundo que afasta a questão do real contexto que a produz, uma sociedade que gera desigualdade e que tem múltiplas expressões da violência, que ganha espaço na grande mídia e nas estatísticas nacionais e que resulta em políticas restritivas, quando o fenômeno é meramente associado à criminalidade (CONSELHO FEDERAL DE SERVIÇO SOCIAL, 2015).

\footnotetext{
${ }^{6}$ Nota Pública do CFESS sobre a redução da idade penal.
} 
Quando questionados/as se a formação em Serviço Social proporcionou reflexões acerca das temáticas elencadas, apenas duas entrevistas apontaram que o curso deixou a desejar no aprofundamento de tais discussões, as demais apontaram que a partir da sala de aula, de palestras e outros eventos os temas foram abordados, tendo a formação profissional em Serviço Social proporcionado uma abertura à processos mais críticos de reflexão e desconstrução, como podemos observar nas falas:

\begin{abstract}
Sim, através de processo de desconstrução. O Serviço Social proporciona ao aluno, se ele quiser, enxergar novos horizontes e principalmente perceber as contradições da sociabilidade em que estamos inseridos (Entrevistado/a 02).

Sim, todas as disciplinas lhe direcionam à compreensão por um viés crítico, entender a realidade social e perceber as diversas expressões da Questão Social, dentre elas as opressões e tendências conservadoras advinda do conflito entre capital e trabalho (Entrevistado/a 06).
\end{abstract}

Percebemos, através dos relatos é que o debate vem sendo suscitado dentro do curso, entretanto, "[...] a maneira como cada estudante percebe esse processo vai depender de sua socialização, de como encara o debate de construção e desconstrução de valores incidindo no modo como se porta ante essas reflexões" (PINHEIRO, 2013, p. 184). Ou seja, não necessariamente todos os indivíduos saem com o mesmo tipo de síntese em relação a alguns elementos colocados durante o processo formativo, sobretudo pelos aspectos que foram construídos ao longo de suas trajetórias pessoais, na vivência dos seus respectivos grupos sociais, valores culturais, religiosos, etc.

Por essas questões, é imprescindível que o elemento ético seja sempre ponderado e aprofundado na formação profissional, tanto durante a graduação como depois dela, tendo em vista que é somente a partir do momento que o indivíduo consegue ter a consciência filosófica, de um posicionamento crítico diante da realidade, que este vai conseguir perceber que o elemento moral que está balizando o seu posicionamento precisa ser desconstruído tendo em vista que a moral é uma reprodução quase que automática de valores que foram apreendidos sem muita reflexão e que são apropriados pelo conservadorismo como forma de naturalização e reprodução de seus pressupostos.

É preciso considerar também que, são evidentes os avanços alcançados a partir da apropriação de um referencial teórico crítico pela profissão, que tem possibilitado uma melhor reflexão acerca dos fundamentos da ética e das possibilidades e entraves na realização do exercício profissional em seu cotidiano, contudo, os obstáculos postos pela sociabilidade burguesa para a realização de uma ética emancipadora, somados aos elementos próprios da formação histórica do Brasil, acabam por contribuírem para que haja um predomínio de uma moralidade conservadora no país (BONFIM, 2015).

Sobre o impacto do conservadorismo na dimensão política de trabalho dos/as assistentes sociais, seis dos/as entrevistados/as não responderam ao questionamento ou afirmaram não se sentirem seguros/as para expressar algum argumento. Daqueles/as que responderam, as afirmações se deram no sentido de que o avanço do conservadorismo tem incidido diretamente na materialização de exercício profissional crítico, colocando aos profissionais inúmeros desafios, inclusive do ponto de vista organizativo, da burocratização dos espaços e do retorno à intervenções de cunho subjetivo e individualizado como demonstrado: 
Incide no exercício profissional afastando-o das lutas e bandeiras que a categoria defende. Inviabiliza o acesso dos usuários aos serviços na perspectiva da garantia de direitos, pauta seu exercício na subjetividade e nas suas crenças (Entrevistado/a 01).

O profissional passa a se deparar com diversas situações onde a sua prática bate de frente com as novas configurações tomadas pelas políticas sociais que lhes são postas, deixando o trabalho do assistente social cada vez mais fragilizado e burocratizado, exigindo do profissional uma postura de enfrentamento diário para a efetivação de sua prática profissional (Entrevistado/a 15).

Com relação aos desafios enfrentados pelo Serviço Social contemporâneo para a materialização do projeto ético-político sob a égide do avanço do conservadorismo, os/as estudantes afirmaram em suas respostas que as maiores dificuldades para a sua efetivação encontram-se na própria lógica burguesa, no retrocesso vivenciado no campo dos direitos sociais e sua efetivação, na precarização dos espaços de formação profissional e mais uma vez, na dificuldade de organização política, como demonstrado abaixo:

Agir de forma crítica, criativa e propositiva, seguindo as dimensões ético-políticas, técnico-operativas e teórico metodológica, como pressupõe o projeto profissional tem sido um grande desafio dentro da lógica do sistema capitalista, tendo em vista a crescente precarização da formação profissional, das condições de trabalho, da autonomia cada vez mais restrita e do próprio conservadorismo que avança na sociedade (Entrevistado/a 10).

Ao final, foi solicitado no questionário que os/as estudantes propossem sugestões para o debate do conservadorismo e as pautas relacionadas na formação profissional em Serviço Social no IFCE. Os apontamentos se deram no sentido de aprofundar o debate em espaços para além da sala de aula, maior incentivo para a aproximação com os movimentos sociais, discutir com maior frequência temas polêmicos e que encolvem o exercício e a formação dos/as estudantes e assistentes sociais, além da criação de grupos de estudo que tratem do conservadorismo.

\section{CONSIDERAÇÕES FINAIS}

O trato teórico-metodológico adotado nesse estudo teve como elemento basilar o entendimento acerca dos impactos do conservadorismo para a profissão e suas atuais formas de expressão a partir do entendimento dos/as estudantes em fase de conclusão do curso de Serviço Social do IFCE Campus lguatu. Esse entendimento muito nos diz sobre o direcionamento dado à formação profissional neste curso e também como isso irá incidir no exercício desses/as futuros/as profissionais.

Tendo como base norteadora os objetivos elencados, o que se pode considerar é que o entendimento apresentado pelos estudantes acerca do conservadorismo se deu de forma razoável, mas sem grandes aprofundamentos, o que aponta para a necessidade de uma maior ênfase para essas discussões e que as mesmas sejam incorporadas com maior densidade nas disciplinas do curso, sobretudo daquelas que não compõe o núcleo dos fundamentos da profissão mas que tem relação direta com o conservadorismo.

Faz-se necessário o entendimento desses/as estudantes das bases de constituição do conservadorismo e de como este está presente na tessitura das relações sociais, do

Temporalis, Brasília (DF), ano 19, n. 37, p. 151-171, jan./jun. 2019. | ISSN 2238-1856 
fortalecimento do fundamentalismo religioso e das manifestações de preconceito e discriminação cada vez mais presentes no cotidiano. Cabe entender também como essa vertente perpassa a construção e efetivação das políticas sociais e consequentemente do exercício profissional, tendo em vista às ameaças ao retorno de práticas imediatistas, burocratizadas e de cunho assistencialista.

No que diz respeito às expressões do conservadorismo no cotidiano do curso, o que se pôde observar foi que estas se dão a partir de posturas moralista, individualizadas, policialescas por parte de sujeitos que o compõem e do próprio caráter da instituição, sendo essa uma dificuldade enfrentada para a própria materialização de uma vertente de formação crítica. Além disso, o crescimento da pós-modernidade foi apontada como uma ameaça a um projeto de formação crítico.

O entendimento dos/as estudantes acerca das pautas societárias que envolvem o conservadorismo se dá, em sua grande maioria, em consonância com os posicionamentos feitos pelo conjunto representativo do Serviço Social e que aponta para o combate de posturas que de alguma forma firam os direitos e liberdades da pessoa humana, reafirmando a luta contra qualquer forma de preconceito, discriminação, violência e estigma.

Diante do exposto, é imprescindível considerar que para se garantir o fortalecimento da direção ético-política da profissão em qualquer espaço, é preciso continuar a garantir/fomentar e expandir espaços de debate onde se possa viabilizar a desconstrução de desvalores e a construção de novos valores pautados numa sociedade emancipada, sem desconsiderar, é claro, os limites que possui essa formação perante algo muito maior e complexo que é a formação subjetiva desses sujeitos que estão intrinsecamente envoltos em uma conjuntura que fortalece cada vez mais o conservadorismo em suas mais diversas expressões (PINHEIRO, 2013).

Além disso, o fortalecimento de espaços de formação e organização política dentro da categoria através da articulação entre profissionais, docentes e estudantes com os movimentos sociais torna-se central no combate ao avanço do conservadorismo no Serviço Social.

\section{REFERÊNCIAS}

BARROCO, Maria Lucia Silva. Ética e Serviço Social: fundamentos ontológicos. São Paulo: Cortez, 2001.

BRAGA, Maria Elisa dos Santos; MESQUITA, Marylucia; MATOS, Maurílio Castro de. Descriminalização e Legalização do Aborto no Brasil: uma luta histórica do movimento feminista, incorporado à agenda do conjunto CFESS-CRESS. Inscrita, Brasília: CFESS, ano 10, n. 14, 2013.

BONFIM, Paula. Conservadorismo moral e Serviço Social. Rio de Janeiro: Lumen Juris, 2015.

BOSCHETTI, Ivanete. Expressões do Conservadorismo na Formação Profissional. Serviço Social e Sociedade, São Paulo: Cortez, n. 124, 2015. 
CONSELHO FEDERAL DE PSICOLOGIA. Nota do Conselho Federal de Psicologia em defesa da Resolução 01/99. Brasília, 12 set. 2018. Disponível em: http://site.cfp.org.br/tag/curagay/. Acesso em: 10 jan. 2018.

CONSELHO FEDERAL DE SERVIÇO SOCIAL. CFESS Manifesta: edição especial em defesa do Estado laico. Brasília (DF), 2016.

CONSELHO FEDERAL DE SERVIÇO SOCIAL. Nota Pública do CFESS sobre a Redução da Idade Penal. Brasília (DF), 17 mar. 2015. Disponível em:

http://www.cfess.org.br/visualizar/noticia/cod/1162. Acesso em: 10 jan. 2018.

CONSELHO FEDERAL DE SERVIÇO SOCIAL. CFESS Manifesta: dia latino-americano e caribenho de luta pela descriminalização e legalização do aborto. Brasília (DF), 2011.

ESCORSIM NETTO, Leila. O conservadorismo clássico: elementos para sua caraterização. São Paulo: Cortez, 2011.

IAMAMOTO, Marilda Vilela. Renovação e conservadorismo no Serviço Social: ensaios críticos. São Paulo: Cortez, 2011.

INSTITUTO FEDERAL DE EDUCAÇÃO, CIÊNCIA E TECNOLOGIA DO CEARÁ. Relatório do Departamento de Registo Acadêmico. Fortaleza, 2017.

MARCONI, Marina de Andrade; LAKATOS, Eva Maria. Metodologia científica. São Paulo: Atlas, 2000.

MINAYO, Maria Cecília de Souza. Pesquisa Social: teoria, método e criatividade. 26. ed. Petrópolis: Vozes, 2010.

MOREIRA, Ana Samilly Alexandre; OLIVEIRA, Luma Rodrigues de; ALBUQUERQUE, Cynthia Studart. Transformações do Capitalismo Contemporâneo e suas Implicações para as Politicas Sociais. In: COLÓQUIO SOCIEDADE, POLÍTICAS PÚBLICAS, CULTURA E DESENVOLVIMENTO, 3., 2013, Crato. Anais [...]. Crato: URCA, 2013.

NETTO, José Paulo. Ditadura e Serviço Social: uma análise do Serviço Social no Brasil Pós64. São Paulo: Cortez, 2011.

NETTO, José Paulo. Introdução ao Método na Teoria Social. In: SERVIÇO Social: direitos sociais e competências profissionais. Brasília (DF): CFESS; ABEPSS, 2009.

ORTIZ, Fátima Grave. O Serviço Social no Brasil: os fundamentos de sua imagem e da auto-imagem de seus agentes. Rio de Janeiro: E-papers, 2010.

OLIVEIRA, Michele Ribeiro. Pensamento Conservador, Teoria Social e Serviço Social: elementos para debate. In: CONGRESSO BRASILEIRO DE ASSISTENTES SOCIAIS, 15., 2016, Recife. Anais [...]. Recife: CBAS, 2016.

PINHEIRO, Paulo Wescley Maia. Serviço Social e neoconservadorismo religioso: a percepção dos/as estudantes e os desafios para o projeto ético-político. Dissertação

Temporalis, Brasília (DF), ano 19, n. 37, p. 151-171, jan./jun. 2019. | ISSN 2238-1856 
(Mestrado em Serviço Social, Trabalho e Questão Social)-Universidade Estadual do Ceará, Fortaleza, 2013.

RICHARDSON, Roberto Jarry. Pesquisa social: métodos e técnicas. 3 ed. São Paulo: Atlas, 2015.

SANTOS, Josiane Soares. Neoconservadorismo pós-moderno e Serviço Social. São Paulo: Cortez, 2007.

\section{Ana Samilly Alexandre Moreira Autora}

Graduada em Serviço Social pelo Instituto Federal de Educação, Ciência e Tecnologia do Ceará (IFCE). Especialista em Serviço Social, Política Social e Seguridade Social pela Faculdade Vale do Salgado (FVS). Mestranda em Serviço Social, Trabalho e Questão Social pela Universidade Estadual do Ceará (UECE). Professora do curso de Serviço Social pela mesma universidade. Pesquisadora do Laboratório de Pesquisas e Estudos em Serviço Social (LAPESS) e do Grupo de Pesquisa Ontologia do Ser Social, História e Emancipação Humana (GPOSSHE) da Universidade Estadual do Ceará, onde coordena o grupo de estudos sobre conservadorismo e realidade brasileira. Possui afinidade às seguintes temáticas: conservadorismo, direção ético-política e formação profissional em Serviço Social.

Mônica Ivo de Oliveira Co-Autora orientando na elaboração do artigo.

Mestrado profissional em andamento em Políticas Públicas com Ênfase em Saúde. Holding Britânia UniGrendal. Especialização em Docência do Ensino Superior. Centro Universitário Dr. Leão Sampaio, UNILEAO. Especialização em Direitos das Famílias. Universidade Regional do Cariri, URCA. 